\title{
Central Nervous System Leukemia on Magnetic Resonance Imaging
}

\author{
Takaaki Konuma, Jun Ooi, Satoshi Takahashi, Akira Tomonari, Nobuhiro Tsukada, \\ Seiko Kato, Senji Kasahara, Kaoru Uchimaru and Arinobu Tojo
}

Key words: CNS, leukemia, MRI

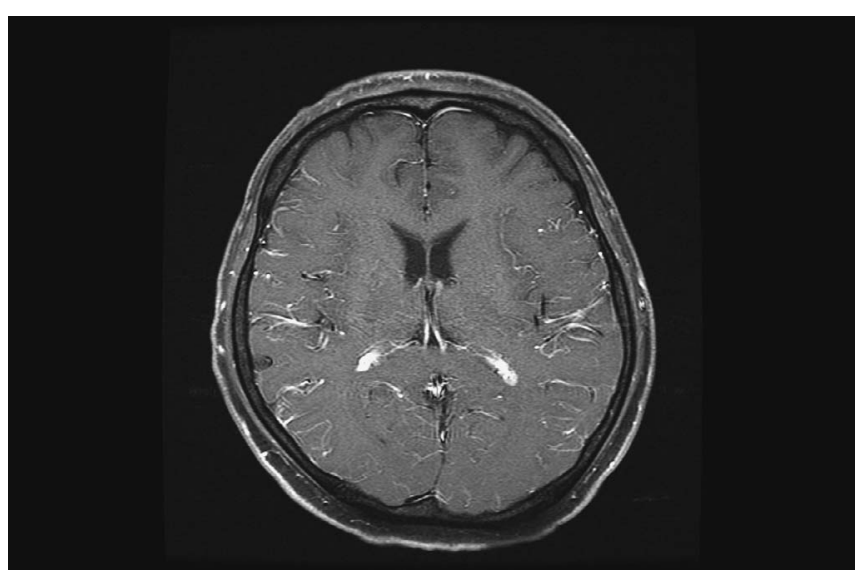

Picture 1.

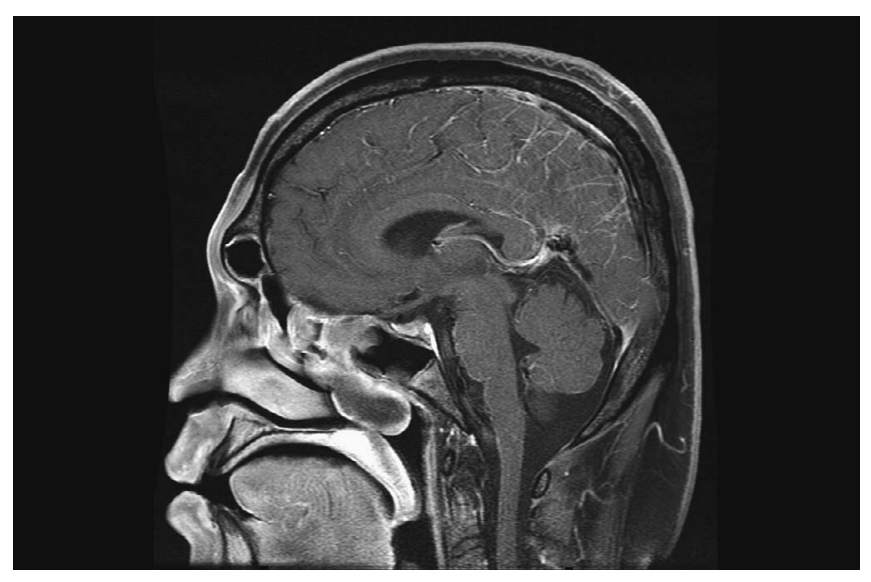

Picture 2.

(Inter Med 47: 477, 2008)

(DOI: 10.2169/internalmedicine.47.0688)

A 32-year-old man 5 years previously received allogeneic bone marrow transplantation from his mother for Philadelphia chromosome positive acute lymphoblastic leukemia. He presented with headache, nausea, and pain in the left arm. The neurologic examination revealed no abnormalities except for stiffness of the neck. Gadolinium-enhanced $\mathrm{T}_{1^{-}}$ weighted magnetic resonance imaging (MRI) showed diffuse contrast enhancement in the cerebral sulcus (Pictures 1,2). Lumbar puncture revealed the presence of lymphoblasts $\left(1,109 / \mathrm{mm}^{3}\right)$. Fluorescence in situ hybridization analysis demonstrated that most of the cells in the cerebrospinal fluid (CSF) were Philadelphia chromosome positive, which confirmed the diagnosis of central nervous system (CNS) leukemia. The patient was treated with intrathecal chemotherapy. The number of lymphoblasts in the CSF was gradually decreased and the symptoms were improved. He experienced a bone marrow recurrence 2 months after CNS relapse and died 18 months later. This case shows that enhanced MRI is also useful in the diagnosis of CNS leukemia.

Department of Hematology and Oncology, Institute of Medical Science University of Tokyo, Tokyo

Received for publication October 23, 2007; Accepted for publication November 12, 2007

Correspondence to Dr. Takaaki Konuma, tkonuma@ims.u-tokyo.ac.jp

(C) 2008 The Japanese Society of Internal Medicine Journal Website: http://www.naika.or.jp/imindex.html 